\title{
ANAESTHESIA AND THE THYROID GLAND: A REVIEW
}

\author{
AzMy R. Boutros, M.B., CH.B., D.A., F.F.A.R.C.S. ${ }^{*}$
}

\section{Chemical, Physiological and Pharmacological Considerations}

The function of the thyroid gland is to synthesize, store and release iodine containing hormones which, after transport in the blood, act upon tissues to alter the rate of a number of intracellular processes.

The volume of literature on this subject is enormous but owing to the limited space available, this review will necessarily be rather concise. The reader who is seeking more detailed information is referred to the excellent papers by Solomon and Dowling, ${ }^{1}$ DeGroot ${ }^{2}$ and Hamolsky and Freedberg. ${ }^{3}$

\section{Chemistry, Synthesis and Fate of the Thyroid Hormones}

The sequence of events in the manufacture of the thyroid hormones is as follows (Fig. 1): (1) Uptake of iodides by the gland; (2) Oxidation of these iodides to elemental iodine; (3) The iodination of tyrosine; (4) The conversion of diiodotyrosine into thyroxine.

In summary, ingested iodine reaches the serum in the form of the iodide ion. Part of the circulating iodine is excreted in the urine, the rest achieves a thyroid to serum concentration gradient for iodide of approximately 25 to 1 .

In the thyroid gland, the iodide ion is oxidized by one or more enzyme systems to elemental iodine.

The elemental iodine then iodinizes the tyrosine molecule within the thyroglobulin molecule to form 3-monoiodotyrosine (3MIT) or 3-5 diiodotyrosine (3-5 DIT). Thyroxine $\left(\mathrm{T}_{4}\right)$ is formed by the oxidative coupling of two molecules of 3-5 DIT with the loss of one alanine side chain.

The mode of formation of $3,5,3^{\prime}$ triiodothyronine $\left(\mathrm{T}_{3}\right)$ is not quite clear. However, there are two possible pathways: $(a)$ oxidative coupling of one 3MIT and one 3,5-DIT molecules with the loss of one alanine side chain and $(b)$ removal of one iodine atom (by deiodination) from the thyroxin molecule.

All the above-mentioned processes occur within the thyroglobulin molecule, which is a protein of high molecular weight.

Thyroxine $\left(\mathrm{T}_{4}\right)$ and triiodothyronine $\left(\mathrm{T}_{3}\right)$ are then set free probably through enzymatic proteolysis of the thyroglobulin molecule, thus enabling these hormones to enter the blood stream.

In the serum $\mathrm{T}_{4}$ and $\mathrm{T}_{3}$ become attached to certain fractions of the plasma proteins (mainly thyroxine binding globulin TBG and thyroxine binding prealbumin TBPA) and they circulate in the blood in this form, thus constituting what is known as serum protein-bound iodine (SPI). How thyroxine is exchanged

*From the Department of Anaesthesia, University of Saskatchewan, Saskatoon, Saskatchewan.

Can. Anaes. Soc. I., vol. 8, no. 6, November, 1961 
${ }_{\mathrm{H}}^{\mathrm{CH} 2} \underset{\mathrm{LH} 2}{\mathrm{CH}} \mathrm{COOOH}^{\mathrm{C}}$

TYROSINE

$\mathrm{NOH}_{\mathrm{NH} 2}^{\mathrm{CH}}$

3 MONOIODOTYROSINE

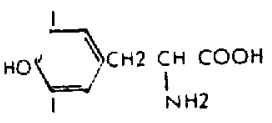

3.5 DIIODOTYROSINE

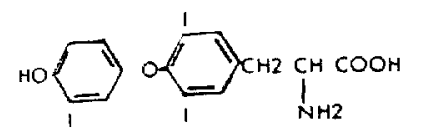

3 3,3 TRIIODOTHYRONINE

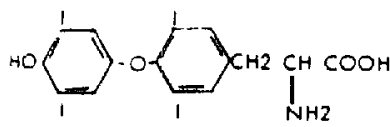

THYROXINE

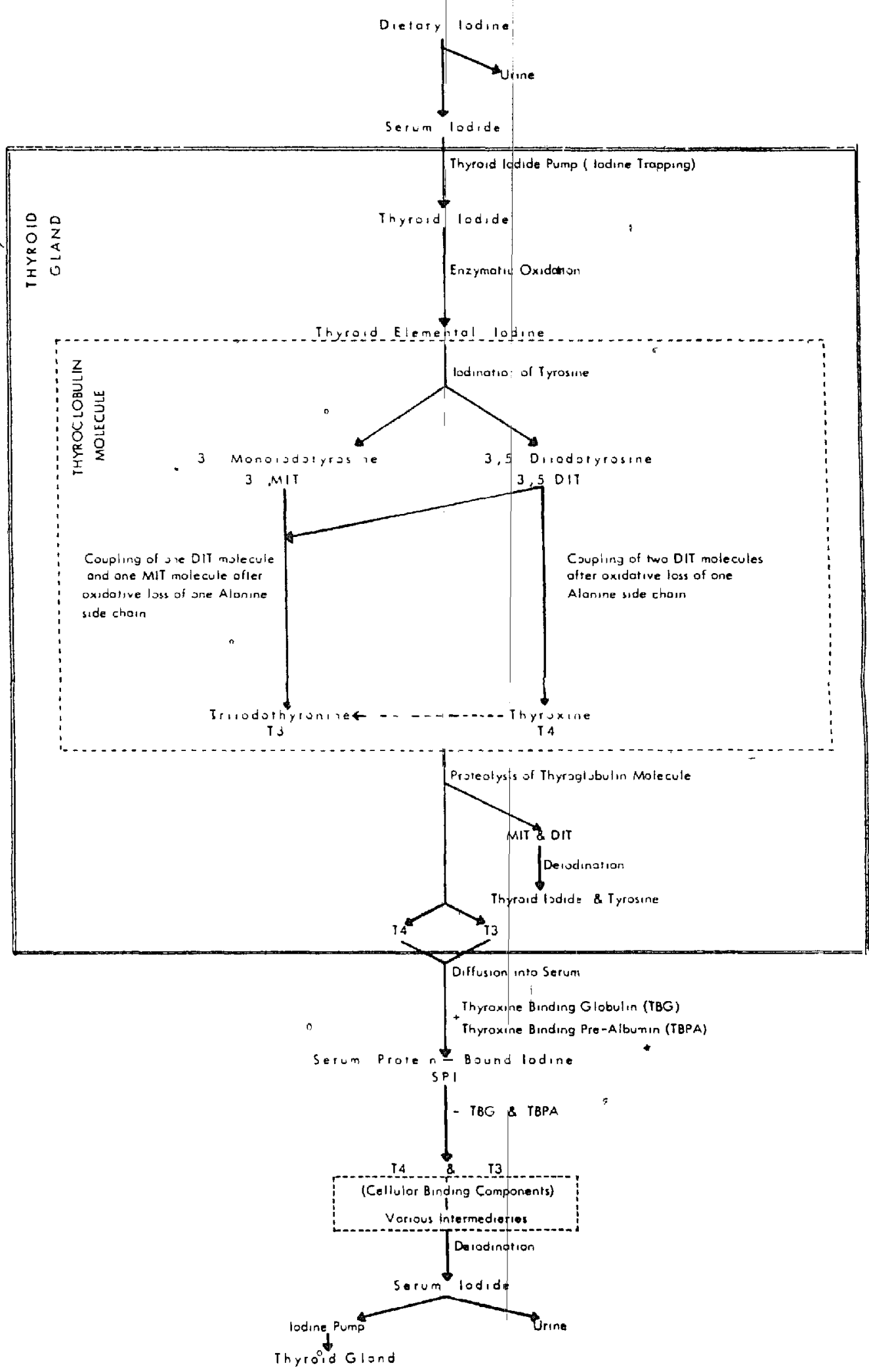

Figure 1. Sequence of events in Thyroid Hormogenesis. I Based on a diagram by Solomon \& Dowling.

from extracellular binding components (TBG and TBPA) to intracellular sites of metabolic degradation or utilization, is still unknown.

Again, the mode of action of thyroxine on the different intracellular processes is still shrouded in darkness and although it has been the subject of extensive research ${ }^{1}$ and literally hundreds of articles, our knowledge about this point is still sketchy. Following this missing link, the picture becomes clear again. Final deiodination of the end-products of intracellular metabolic processes results in 
free iodides, which leave the cells and appear in the blood as serum iodide. This is partly excreted in the urine and partly retrapped by the thyroid.

\section{Regulation of Thyroid Function}

\section{A. ROLE OF CENTRAL NERVOUS SYSTEM}

There has been a great deal of work on this subject. The available data lead to the hypothesis that various hypothalamic nuclei secrete one or more neurohumoral substances which pass to the capillary plexus of the median eminence and thence down the portal veins to the adeno-hypophysis, where thềy alter the rate of synthesis or rellease (or both) of the thyroid stimulating hormone (TSH), adrenodorticotropic hormone (ACTH) and gonadotropic hormone. ${ }^{*}$ So far, with the exception of vasopressin, no hypothalamic neuro-secretory substance has been identified, and thus the concept remains a probable but unproved hypothesis. However, one may conclude from present evidence that an intact hypothalamo-hypophyseal system is necessary for the maintenance of normal output of TSH in the resting state, for the full degree of normal response to a reduction in the circulating level of thyroid hormone, and for the stimulatory or inhibitory adaptations to stressful stimuli. On the other hand, inhibition of the production of TSH by added thyroid hormone occurs despite interruption of the hypothalamo-hypophyseal pathway. ${ }^{1}$ Indeed, the injection of minute quantities of thyroxine directly into the adenohypophysis appears to shut off release of TSH from that organ. ${ }^{5,6}$ Injection of thyroxin into the anterior hypothalamus may $^{6}$ or may not ${ }^{5}$ release TSH from the hypophysis.

\section{B. ROLE OF ADENOHYPOPHYSIS (Thyroid Stimulating Hormone)}

The adenohypophysis exerts an important influence over thyroid function through the thyroid stimulating hormone (TSH) secreted by the angular basophils in the anterior pituitary. Present evidence ${ }^{2}$ suggests that changes in the serum protein-bound iodine (SPI) affect the adenohypophysis in one of two ways: (1), by affecting a receptor centre in the hypothalamus, which in turn regulates the activity of anterior pituitary through a hypothetical neurohumoral mechanism via the hypothalamo-hypophyseal portal system of blood vessels; (2), by directly affecting the adenohypophysis without the intervention of the hypothalamus.

A decrease of the SPI will lead to stimulation of the angular basophils (Thyrotrophs) of the adenohypophysis to produce more TSH. This will then directly affect the function of the thyroid gland. TSH will cause increased thyroid iodide trapping, more rapid iodide oxidation and binding and more rapid thyroglobulin proteolysis which will result in more thyroxine being thrown into the circulation, thus correcting the initial condition of low SPI. An increase in SPI will, on the other hand, depress the adenohypophysis, which will secrete less TSH, thus discouraging the sequence of events in the thyroid gland that would lead to more thyroxine secretion.

This thyroid-adenohypophyseal interrelationship seems to be disturbed in 
cases of hyperthyroidism. Greer found that the patient with Graves' disease differed from the normal human in that the administration of thyroid hormone failed to suppress his thyroidal uptake of $I^{131}{ }^{7,8}$ This abnormality is often present in persons in the euthyroid stage of Graves' disease and it may persist for long periods after successful treatment of the hyperthyroidism. It thus seems to be a fundamental characteristic of the pathological physiology of Graves' disease, rather than a phenomenon related to the increased circulating thyroxine levels or its consequences. However, the finding of non-suppressibility of thyroid function by exogenous hormone has not solved the controversy as to whether the increased thyroid hormone production and release in active Graves' disease results from an uncontrolled excess of TSH production or from some autonomous intrinsic alteration in thyroid function. ${ }^{7}$ TSH was found to be composed of two distinct fractions ${ }^{9}:(a)$ an exophthalmos-producing substance which produces severe exophthalmos in laboratory animals; (b) a thyroid stimulating fraction which produces hyperplasia of the thyroid gland. These findings may clarify the lack of correlation between hyperthyroidism and exophthalmos and elucidate the role of the pituitary gland in exophthalmos.

C. ROLE OF THYROID GLAND (Thyroidal Auto-Regulation)

Despite the overpowering effects of $\mathrm{TSH}^{\circ}$ on various stages of thyroid activity, the thyroid gland retains some degree of autonomous behavior:

1. Regulation of the iodide pump. Regardless of total organic iodine concentration in the thyroid a small amount of recently bound iodine appears to inhibit the iodide pump. It thus seems that one or more specific iodine containing compounds within the thyroid (rather than total organic iodine concentration) directly depress the iodide pump in opposition to the stimulating effect of TSH. ${ }^{10,11}$

2. Regulation of organic $I^{131}$ release from the thyroid. In rat and man, receiving propylthiouracil, the daily output of hormonal iodine from the thyroid gland falls by an amount constantly proportional to the declining store of hormonal iodine in the gland. ${ }^{12,13}$ This phenomenon is clearly non-hypophyseal in origin since any fall in the blood level of thyroid hormone caused by propylthiouracil would lead to increased TSH output and a corresponding increase in the release of hormone from the thyroid rather than the observed progressive decrease.

It thus seems that the thyroid gland is adapted to guard its own stores while the TSH releasing mechanism responds to the requirements of the tissues for thyroid hormone.

\section{ROLE OF IODINE ${ }^{14}$}

* 1. Effects of Iodine Deficiency. Adequate daily iodine intake is essential for the maintenance of normal thyroid function. Iodine deficiency stimulates TSH production, which in turn acts on the gland, producing hypertrophy and hyperplasia. The epithelial cells of the gland change from cubical to columnar and their number per given follicle greatly increase. The amount of colloid material and the total iodine content of the gland are diminished. Thus, the over-all 
picture of the thyroid in iodine deficiency is one of a hypertrophic, hyperplastic gland, low in iodine content and functioning at maximum capacity. The fact that the metabolic rate is not lowered indicates that the gland is capable of producing sufficient amounts of the hormone. This condition is known as simple or nontoxic goitre. Correction of the deficiency produces marked involution of the gland. The acini become engorged with colloid and, although the gland is functioning normally, it is quite enlarged owing to its high content of colloidal material despite the fact that the epithelium has returned to normal.

2. Effects of Excessive Ingestion of Iodide. These are even more complex than the effects of iodide deficiency.

(a) It markedly decreased the rate of organic binding of iodine within the thyroid. Some monoiodotyrosine is formed but the diiodotyrosine synthesis is minimal. ${ }^{15}$ It has even been reported that chronic ingestion of iodides has led to the development of myxoedema and iodine kinetics indicative of a permanent block in hormogenesis. ${ }^{16}$

(b) It reduces thyroid-serum ratio $(\mathrm{T} / \mathrm{S})$ by both intrathyroidal and hypophyseal mechanisms.

(c) It leads to a temporary increase in circulating thyroid hormone and to a decrease of TSH output.

(d) It inhibits the accelerated rate of hormone release characteristic of hyperthyroid patients or normal individuals receiving TSH. The untreated euthyroid individual is not affected. Whether excess iodide intake acts by inhibiting TSH output or by opposing the action of TSH on the thyroid gland, has not been settled yet. ${ }^{13,17,18}$

\section{Laboratory Diagnostic Tests of Thyroid Function and Disease ${ }^{19}$}

\section{A. BASAL METABOLIC RATE}

The BMR is the total of the various factors affecting energy exchange of all the tissues of the body. Its diagnostic accuracy is rather low. However, it can be of some value if the techniques are accurate, particularly if it shows definite changes after therapeutic tests. Thiopentone or oral pentobarbitone are used to correct the non-thyrogenic increased metabolic rate of CNS hyperactivity.

\section{B. SERUM PROTEIN-BOUND IODINE (SPI)}

This is a measure of the amount of iodine (mainly in the form of thyroxine and triiodothyronine) bound to plasma proteins at the time the blood sample was drawn. The blood level of SPI is actually dependent on two factors: (1) the rate of release of these components from the thyroid into the circulation; (2) the rate of transfer of the hormones from the circulation into the peripheral tissues.

The normal range of SPI is 3.5-8.0 micrograms per 100 cc. serum. In hypothyroidism the range is $0-3.5$ microgram per cent while in hyperthyroidism it is over 8.0 micrograms. SPI is increased in hyperthyroidism, thyroiditis, normal pregnancy, certain cases of hepatitis particularly in early stages, ${ }^{20}$ ingestion of 
dessicated thyroid or thyroxine and administration of brganic iodine (contrast medium). SPI is lowered in hypothyroidism, whether primary or secondary to hypopituitarism, in nephritis, after ingestion of mercury compounds, and in certain cases receiving cortisone or ACTH therapy. ${ }^{21}$

Diagnostic accuracy is generally of the order of $90<95$ per cent.

\section{RADIOACTIVE IODINE ( ${ }^{131}$ ) UPTAKE BY THE THYROID}

This is actually the over-all resultant of the following variables: (1) uptake of iodide; (2) its conversion to hormonal form; (3) release of hormone into circulation; (4) rate controlling effects of TSH; (5) urinary excretion of iodide. Radioiodine uptake is increased. in hyperthyroidism, certain cases of renal diseases including nephritis, certain cases of hepatic disease, diet low in iodine, certain cases of relatives of hyperthyroid patients ${ }^{22}$ and $/$ rertain cases of endemic goitre.

The uptake is decreased in hypothyroidism both primary and secondary, corticoids and ACTH therapy in certain patients, use of desiccated thyroid or thyroxine, exposure to percholate ions, ${ }^{23}{ }^{24}$ exposure to cobalt ${ }^{25}$ and prolonged administration of large doses of iodine. ${ }^{16}$

The diagnostic accuracy of this test varies between 70 and 95 per cent.

D. OTHER TESTS OF THYROID FUNCTION USING RADIOISOTOPE\$

(1) Thyroid plasma iodide clearance:

Thyroid accumulation of iodide per unit time

Plasma concentration of iodide

Normal values 3-45 ml./min.-mean 17

(2) Conversion ratio: a reflection of the percentage of circulating $\mathrm{I}^{131}$ at a given instant that has been converted to hormonal form.

(3) Salivary excretion of $I^{131}$ : is a reflection of the plasma levels of $I^{131}$.

(4) Red cell uptake of $\mathrm{I}^{131}$ labelled triiodothyroxine: this is an in vitro test. It is fairly accurate and obviates the necessity of giving the patient radioactive isotopes.

(5) Thyroid suppression test: this is limited to differentiation of hyperthyroidism from euthyroidism. For further details on the subject of laboratory diagnostic tests, the reader is referred to the papers by Hamolsky and Freedberg. ${ }^{19}$

\section{Factors Affecting Thyroid Function}

\section{A. NERVOUS FACTORS}

1. Autonomic Nerve Supply to the Thyroid Gland. ${ }^{26}$ The thyroid derives its nerve supply from the vagus and the sympathetic. The sympathetic fibres leave the spinal cord between the second and fifth thoracic segments. After being relayed in the superior and middle cervical ganglia these fibres are carried to the gland through the superior laryngeal nerves and along the blood vessels. 
It is probable that the thyroid nerves are purely vasomotor in function and influence the activity of the gland indirectly through altering its blood supply.

2. Hypothalamic Influence. This has been the subject of extensive research, but the results are still not conclusive. The presence of a thyrotropic "centre" in the hypothalamus has been suggested but as yet not proved. The exact location of this hypothetical entre may be inferred from the fact, that only anterior hypothalamus lesions in laboratory animals produce significant changes in the thyroid while posterior hypothalamic lêsions in all species studied are ineffective. ${ }^{10,27,28,29.30}$ The question of hypothalamo-hypophyseal relationship has already been discussed.

3. Pituitary Gland. The important role the anterior pituitary plays in regulating and affecting the functions of the thyroid gland has been mentioned.

Complete hypophysectomy in man leads to significant fall in thyroidal I ${ }^{131}$ uptake and SPI levels within two weeks. ${ }^{31}$ Incomplete hypophysectomy in man produced no changes in those two tests.

\section{B. EFFECTS OF ACUTE STRESSFUL CONDITIONS}

1. Major Surgery or Trauma. Reports on the effects of major surgery or trauma on the function of the thyroid gland are rather conflicting. Shipley ${ }_{\mid}$and MacIntyre $^{32}$ found that the stress of major surgery causes a release of the thyroid hormone from the gland and increased utilization of hormone by the peripheral tissues. They also described an increased turnover of $\mathrm{I}^{131}$ following surgical stress.

Engstrom and Markardt ${ }^{33,34}$ reported that the serum levels of precipitable iodine (SPI) remained constant under conditions of severe stress.

According to Moore ${ }^{35}$ patients undergoing surgery or trauma show increased oxygen consumption, but he thought that this was not because of changes in thyroid function and that there was no marked alteration in thyroid activity.

Goldenberg et al., ${ }^{36}$ on the other hand, demonstrated an increase in circulating thyroid hormone as measured by the conversion ratio (SPI ${ }^{131}$ ) in a group of patients during operative trauma. They also found that patients who had chronic illnesses or recent acute stress prior to the study, did not show increased conversion ratios during operation.

This group of workers suggests that thyroid activation may play a very important role in the entire endocrine-metabolic response to operative stress and that, in the absence of thyroid response, the entire chain of post stress events in the organism may be quite different from the standardized description.

2. Traumatic Shock. Oppenheimer et al..$^{37}$ conducted a series of experiments on animals to determine the effects of traumatic shock on thyroid function. They found that traumatic shock induced a marked reduction in the thyroidal capacity. to concentrate iodides, as measured by thyroidal clearance of $\mathrm{I}^{131}$. They also found that recently thyroidectomized animals (goats) showed no change in survival times from control values when subjected to the standard injury. Hyperthyroid goats showed marked sensitivity to traumatic shock, a phenomenon which could not be reversed by the administration of cortisone. Animals treated with 
2-4-dinitrophenol (which increases oxygen consumption) showed a decrease in survival time statistically comparable to that induced by thyroxine.

\section{CHEMICAL FACTORS}

\section{Endocrinal:}

(a) Hypophysis cerebri (see above)

(b) Supra-renal glands:

(i) Supra-renal medulla. Brewster et al. ${ }^{38}$ conducted a number of experiments on dogs in an effort to elucidate the adrenal-thyroid interrelationship. Their results were quite impressive and comparable to clinical observations in human beings. They came to the following conclusions: (1) The haemodynamic and metabolic responses to epinephrine and norepinephrine, whether these are reflexly released, injected or infused, may be increased by increased concentration of the thyroid hormone and decreased or abolished in the hypothyroid state. (2) By preventing the release of epinephrine and norepinephrine, a, total sympathetic block diminishes or abolishes the metabolic and haemodynamic changes resulting from thyrotoxicosis, thyroxine injection or thyroid feeding in man and laboratory animals. (3) The physiological effects of thyrotoxicosis are not the results of the isolated action of the thyroid hormones per se but are due to the physiological effects of epinephrine as augmented by the thyroid hormones.

(ii) Supra-renal cortex ${ }^{39}$ In man, $\mathrm{ACTH}$ and cortisone lower the thyroidal accumulation of radioiodine. ${ }^{21,40.41,42.43}$ This can be partly explained by the fact that ACTH and cortisone also increase the renal clearance of iodides. However, this is rather transient and is not an invariable accompaniment of decreased uptake of $I^{131}$. $^{44}$

ACTH and cortisone administration in humans may rather abruptly, if not invariably, diminish the SPI level ${ }^{21,40,44,49,46}$ although they do not alter the thyroxine turnover in the peripheral tissues. These observations suggest that cortisone and ACTH suppress the rate of release of the thyroidal hormone from the gland secondary to suppression of the hypophyseal thyroid stimulating hormone ( TSH).

It must be emphasized, however, that experiments on different animal species may produce quite unsimilar and conflicting results.

(c) Gonads:

(i) Effects of oestrogen. ${ }^{47}$ Administration of oestrogens in both man and woman produces an increase in the SPI concentration. Normally functioning pituitary and thyroid glands are necessary for the reaction to occur. With the discontinuation of oestrogen therapy, the SPI level falls back to control values. This increase of SPI values is thought to be due to increased thyroidal activity and not to an altered rate of disposal of the thyroid hormone. The administration of large doses of oestrogen results in values of SPI which would ordinarily be associated with manifestations of hyperthyroidism. Thus it seems ${ }^{28}$ safe to conclude that under these circumstances there exists an increased tolerance to increased concentrations of the circulating hormone. However, the underlying mechanisms are not. entirely clear. 
(ii) Pregnancy and the thyroid gland. ${ }^{48}$ Radioactive iodine studies in pregnancy show an increased thyroid uptake and conversion of iodide to the hormonal form. SPI is increased from the sixth week of pregnancy until several days post partum. A large number of miscarriages have been observed in cases in which the SPI fails to rise during pregnancy and it was suggested that elevation of the SPI by the administration of thyroid may contribute to a favourable outcome in these cases. The underlying mechanism of this rise in SPI is thought to be the increased serum oestrogen levels in pregnancy.

An increase in the total hormonal turnover is suggested by the normal rate of disappearance from the circulation of administered thyroxine despite the fact that the SPI levels are already high. However, regardless of this suggestion of an increased hormonal turnover, and the clear evidence of thyroid hyperactivity. the pregnant woman rarely presents clinical manifestations of thyrotoxicosis and even when there are such manifestations, they are probably due to the circulatory adjustments consequent to the demonstrated arterio-venous shunts in pregnancy. Again, the rise in oxygen consumption which occurs from mid pregnancy to term and for a variable period post partum is probably due to increased uterine and foetal tissue requirements, foetal movements, mechanical respiratory impedenice and the dynamic circulatory adjustments of the gravid uterus, rather than to primary thyroidal hyperfunction.

(iii) Thyroxine and the placental barrier. ${ }^{49}$ During pregnancy, the SPI level in the maternal blood goes up. The SPI concentration of the cord blood is also higher than that of the normal human adult. Thyroxine probably does not cross the placental barrier; even if it does, the passage must be very slow. Iodine and iodides, on the other hand, cross freely through the placenta.

(iv) Methyl testosterone was found to induce a marked fall in thyroxine binding capacity of the thyroxine binding globulin (TGA) of serum in all patients and a less marked though consistant increase in the fractional rate of thyroxine disappearance from the blood. Other findings were a slight fall in SPI, an increase in circulating free thyroxine and an increase in the amount of thyroxine degraded per day. Decreased thyroxine-binding protein concentration in the serum is probably responsible for these changes. ${ }^{50}$ There was also a consistant rise in serum cholesterol during the administration of methyl testosterone.

(d) Effects of thyroidectomy and radioactive iodine. ${ }^{51}$ Both thyroidectomy and therapeutic doses of radioactive iodine in patients suffering from Graves' disease lead to hypothyroidism of varying severity. However, post-thyroidectomy hypothyroidism is usually mild and transient since remnants of thyroid tissue left in the neck may gradually regenerate sufficiently to produce a normal daily supply of the hormone. Theoretically, the administration of exogenous thyroid might interfere with this regrowth of thyroid remnants. However, this should not discourage the physician from prescribing thyroid if there are definite manifestations of hypothyoidism in such patients.

2. Anti-Thyroid Drugs: Mechanisms of action of anti-thyroid drugs: ${ }^{52,53}$ (a) Destruction of thyroid tissue by radio iodine $I^{131}$. Radioactive isotopes 
of iodine are treated by the body as ordinary iodine ions, thus they are trapped by the thyroid gland where they emit beta and gamma rays. Apart from transient or permanent myxoedema, radio iodine therapy produces no untoward effects except some mild and transient radiation thyroiditis.

(b) Drugs indirectly inhibiting hormone synthesis. These are the agents that depress the production of thyroid stimulating hormone. Iodine administration leads to depressed hormone synthesis (supra). Exogenous thyroxine administration (in non-toxic patients) can be included in this group.

(c) Drugs inhibiting trapping and retention of iodine by the thyroid gland. Thiocyanate is the best example of this group. This ion interferes with thyroid function at the stage of iodine concentration. However, the thyroid gland does not maintain any concentration gradient of thiocyanate against the plasma. Furthermore administration of large doses of iodine will overcome the thiocyanate effect and hormorie synthesis will occur normally although it has been found that very large doses of thiocyanate may inhibit the organic binding of iodine in the thyroid gland as well. ${ }^{54}$ The mode of action of the thiocyanate ion is not known.

Other anions that act in a similar way are the perchlorates, chlorates, hypochlorites, periodates, iodate and to a minor extent the nitrates.

(d) Drugs interfering with hormone synthesis by direct action on the thyroid:

(i) Thiourea and its derivatives. These are by far the most effective antithyroid drug group. They all possess an -SH group which makes them strong reducing agents and it is very likely that this property is intimately concerned with their mode of action. Unlike the thiocyanate group of anions they do not interfere with iodine trapping. The exact nechanism of action of the thiourea drugs is not known yet although there are quite a number of theories: (1) they may inhibit the enzyme system responsible for the oxidation of ionic to elemental iodine; (2) they may compete with iodine for the oxidative enzymes; (3) they may react with elemental iodine thus preventing the latter from iodinating tyrosine.

Yet it is an oversimplification to say that thiourea derivatives block iodination of tyrosine. Pitt-Rivers et al. ${ }^{55}$ have recently shown that large doses of propylthiouracil still allow traces of MIT to be formed. Small doses of the drug result in the formation of large amounts of iodotyrosines with an abnormally high MIT/DIT ratio. ${ }^{56,57}$ Thus it seems that thiourea derivatives decrease the rate of monoiodination of tyrosine but much more strongly inhibit the further iodination of monoiodotyrosine.

(ii) Aminobenzoic acid derivatives, for example sulfonamides, derivatives of para-aminobenzoic acid and para-aminosalicylic acids. The antithyroid potency of most of these agents is not very great and beyond the fact that they interfere with the synthesis of the thyroid hormone, little is known of their mechanism of action.

(iii) Numerous drugs possess some antithyroid activity but again their mode of action is still unknown, for example Resorcinol, m-aminophenol, thiocarbonamides, phenothiazine derivatives (infra) and many others of only academic interest. 


\section{Anaesthetic Agents:}

(a) Thiobarbiturates. These drugs can be considered as derivatives of thiourea and it is not surprising that they share the antithyroid properties of the latter. Thiamylal "sodium 5-allyl-5( 1 methylbutyl) 2 thiobarbiturate" markedly inhibits the uptake of $\mathrm{I}^{131}$ by the rat thyroid. ${ }^{58}$ As with other thiourea derivatives, the mechanism of this antithyroid action is not very clear.

Thiopental (Pentothal ${ }^{\circledR}$ ) influences the thyroid metabolism principally by depriving the thyroid of available iodine. ${ }^{59}$ This influence is not related to the anaesthetic effect, since anaesthetic agents which did not contain $\mathrm{N}-\mathrm{C}=\mathrm{S}$ group. ing did not change the uptake of $\mathbf{I}^{131}$ while other anaesthetic agents containing a thiocarbamate structure have also been shown to have antithyroid activity.

Of greater interest is the finding that a single dose of thiopental produces prolonged inhibition of thyroid activity; after a $40 \mathrm{mg}$. $/ \mathrm{kg}$. dose in rats, 6-7 days were required for complete recovery of thyroid activity. This prolonged inhibition is probably related to accumulation of the metabolic degradation products of thiopental (e.g., thiourea) in the thyroid.

(b) Diethyl ether and cyclopropane. Experiments conducted on Albino rats ${ }^{60}$ investigating the uptake of $\mathrm{I}^{131}, 2$ hours, 4 hours and 24 hours of the postanaesthesia period revealed that both cyclopropane and ether anaesthesia definitely depressed the 2-hour thyroid uptake. This profound influence on the thyroid became insignificant in the 4-hour test. The 24-hour test indicated that there was no appreciable influence of either cyclopropane or ether on the uptake of $I^{131}$. Thiopental administered intraperitoneally significantly depressed the thyroid uptake of $\mathrm{I}^{131}$ in the 2-, 4- and 24-hour tests.

In another series of experiments ${ }^{61}$ it was clearly demonstrated that diethyl ether anaesthesia depressed the release of $I^{131}$ from the rat thyroid blocked with thiouracil, an effect which lasted for at least twelve hours. Thiopental, on the other hand, did not inhibit but possibly slightly increased the release of thyroidal $\mathrm{I}^{131}$ in the post-anaesthesia period. This difference was not accounted for by the sleeping time or the length of inactivity in the post-anaesthesia period.

To sum up, the influence of diethyI ether anaesthesia on the rat thyroid is different from that of thiopental on both thyroidal uptake and release of $\mathrm{I}^{131}$. The difference in the effect on uptake was a quantitative one and could be due to rapid excretion of ether as opposed to the slow excretion of thiopentone. The difference in the effect on radioactive iodine release however, was a qualitative one, as the release rate of $\mathbf{I}^{131}$ from thiouracil blocked gland was markedly slowed by ether anaesthesia and not at all by thiopental.

\section{Miscellaneous Agents:}

(a) Chlorpromazine. ${ }^{62}$ This drug lowers oxygen consumption in basal conditions and inhibits the calorigenic effects of thyroxine administered parenterally.

Chlorpromazine produces a dissociated inhibiting effect on TSH (Thyroid Stimulating Hormone) affecting its metabolic function more intensely than its function of producing thyroid hyperplasia. In some clinical cases of hyper- 
thyroidism and exophthalmic goitre, a reduction of the thyrotoxic and autonomic manifestations, a reduction of the BMR, SPI and in some cases of the goitre itself were obtained after a relatively short period of chlorpromazine therapy.

Previous administration of chlorpromazine stimulates the action of antithyroid drugs.

(b) Procaine. ${ }^{63}$ Doses of $0.5 \mathrm{cc}$. of 2 per cent procaine $\mathrm{HCl}$ produce clear antithyroid action in rats as shown by diminished thyroid $\mathrm{I}^{131}$ uptake and lowered concentration of hormonal iodine in the gland.

\section{PHYSICAL FACTORS}

Changes in external temperature influence the activity of the thyroid gland. Exposure of the body to cold stimulates the thyroid to produce more thyroxine, which helps to increase the metabolic rate and heat production and maintains the body temperature. This is usually associated with characteristic signs of thyroid hyperplasia. If, however, the subject is prevented from shivering by deep anaesthesia, cooling of the body produces marked reduction in thyroidal activity. ${ }^{64}$

\section{Physiological and Pharmacological Actions, of the Thyroid Hormones ${ }^{65}$}

\section{A. CALORIGENIC EFFECTS}

Thyroid hormones increase the rate of tissue oxidation as shown by BMR determination or by determination of oxygen consumption of isolated tissues obtained from animals pre-treated with thyroxine. The effect of the thyroid hormones upon the oxidative mechanisms is not clear. A probable explanation is that thyroxine may act by uncoupling of oxidation and phosphorylation in the cells. ${ }^{66}$ An over-simplified explanation of the underlying processes is all that this paper can cope with and is as follows. ${ }^{67}$

A complex molecule has a higher energy content than the atoms or simpler molecules from which it is built, because of the energy of formation of the chemical bonds which hold it together. This bond energy is liberated when the bonds are broken. Thus, when most organic phosphates are hydrolysed, energy equivalent to about $2000-3000 \mathrm{cal} . / \mathrm{mol}$. is made available as heat, and the bond broken in this process is called a low-energy phosphate bond. Hydrolysis of certain organic phosphates of special structural types releases. energy equivalent to about $12000 \mathrm{cal} . / \mathrm{mol}$., the bond broken in this calse being called a high energy phosphate bond.

These high energy phosphates are important in metabolism for the following reasons: (1) This phosphate group can be transferred directly to another organic molecule without much of the higher energy of its bonding being dissipated as heat. The product is a phosphorylated molecule. (2) In the body, the energy of dissimilation, instead of being lost as heat, is used to synthesize compounds containing high energy phosphate bonds. These compounds are then stored and the energy locked up in them is available to the body for the various metabolic processes or for heat production, etc. 
Thus complete oxidation of one gram-mol.| (180 gm.) of glucose liberates. energy equivalent to 686,000 cal. of heat, most of which is used to synthesize high energy phosphate bonds, while the rest is dissipated as heat.

It is probable that thyroid hormones prevent the use of such energy in the synthesis of phosphate bonds and phosphorylation of lower energy molecules, with the result that most of the energy of oxidation will appear as heat. Thus the oxidative processes are uncoupled from phosphorylation processes.

Thyroxine injection leads to an increase in the oxidative processes after a latent period of approximately 18 hours, while injected triiodothyronine acts after one to two hours. This led to the hypothesis that triiodothyronine may be the active agent at the tissue level, triiodothyronine being formed from thyroxine through a process of partial deiodination. However, the fact that triiodothyronine does not lead to an increase in the oxidative processes when added to tissue slices, in vitro (as with thyroxine) throws a grave doubt over this hypothesis.

The calorigenic action of the thyroid hormones is considerably smaller in very young than in older individuals and is greater in the absence of the thyroid gland, or when the original metabolic level is low.

\section{B. EFFECT OF THYROID HORMONES ON GROWTH}

(1) Absence of thyroid hormones during the growth period leads to retardation of growth, which is resumed when the deficiency is corrected.

(2) Excessive amounts of thyroid in growing individuals leads to abnormally rapid growth.

(3) Normal animals treated with thyroid hormones show increased growth which is almost entirely due to increased food intake.

It is not yet certain whether the growth enhancing effect of thyroid is indirectly mediated through the pituitary gland or whether it is actually a direct effect of the thyroid hormone itself. The former assumption is supported by the observation that thyroid hormone is incapable of inducing growth in hypophysectomized animals.

(4) Thyroid hormone induced differentiation and maturation of tissues, which is quite distinct from the growth enhancing effect; thus, absence of the hormone not only arrests growth in length of bones leading to dwarfism but also causes a delay in the appearance of epiphyseal centres of ossification.

\section{EFFECTS ON SPECIAL METABOLIC PROCESSES}

1. Protein Metabolism. Abnormally large amounts of thyroid hormone enhance protein catabolism leading to a negative nitrogen balance. On the other hand physiological amounts of the hormone favour protein anabolism, thus producing retention of nitrogen and positive balance.

Following thyroidectomy, there is an accumulation of extracellular fluid which is rich in protein. This is the basis of myxoedema in humans. There is also a rise in serum globulin and a fall in serum albumin. Thyroid hormone administration, leads to reversal of these changes.

2. Carbohydrate Metabolism. Thyroid hormone influences the carbohydrate 
metabolism in the following ways: (a) It enhances the absorption of monosaccharides from the intestine. Absence of hormone leads to decreased absorption. ${ }^{68}(b)$ It enhances glycogenolysis. Excessive hormone leads to towering of liver glycogen while thyroidectomy produces increased liver glycogen. ${ }^{69}(c)$ It enhances neoglucogenesis. $(d)$ It increases the utilization of glucose by the tissues, probably through favouring the hexokinase reaction.

3. Lipid Metabolism. Plasma cholesterol levels decrease in hyperthyroidism and increase in hypothyroidism. The presence of excessive amounts of thyroid hormone leads to increased oxidation of fat after the carbohydrate stores have become exhausted. This is accompanied by ketonaemia and ketonuria. However, blood fat values are not influenced by different levels of thyroid function.

4. Creatine Metabolism. Creatine urinary excretion increases following the administration of thyroid hormone and falls to very low levels in hypothyroidism. Creatine tolerance tests show decreased tolerance in hyperthyroidism probably owing to impairment of the capacity of muscle cells to synthesize creatine phosphate from creatine.

5. Vitamin Metabolism

(a) Vitamin A. Lack of thyroid hormone leads to failure of synthesis of vitamin A from carotene, presumably in the liver, and to manifestations of vitamin A deficiency. In hyperthyroidism there are also signs and symptoms of vitamin A deficiency partly due to more rapid destruction and partly to decreased formation of vitamin $\mathrm{A}$ as a result of liver damage.

(b) Vitamin B group. In hyperthyroidism, there is increased demand for this vitamin group, as well as excessive elimination in the urine, leading to increased requirements for vitamin $\mathbf{B}$.

Administration of thiamine, pantothenate and pyridoxine checks the weight loss in animals receiving thyroid hormone, mainly because of improved appetite and increased food consumption.

(c) Vitamin C. Thyroid administration leads to increased requirements for vitamin C. Apart from this, some of the metabolic effects of thyroxine, for example creatinurea, seem to be preventable by the simultaneous administration of ascorbic acid.

\section{Water and Electrolytes}

(a) Water retention is a feature of absence of thyroid hormone. The oedema fluid has a high protein content. Administration of the hormone leads to disappearance of this fluid and diuresis accompanied by sodium diuresis.

Thyroid hormone administration in euthyroid individuals leads to diuresis accompanied by potassium diuresis.

(b) Total blood volume is reduced in hypothyroidism. Plasma volume increases in hyperthyroidism. There is a rise of plasma protein concentration in hypothyroidism and a decrease in hyperthyroidism.

(c) Excessive amounts of thyroid hormone lead to increased excretion of calcium in urine and faeces without significant changes in the serum calcium levels. This may eventually lead to skeletal demineralization unless the excessive loss is corrected by increased intake. 
On the other hand, small doses of thyroid extract given to young growing individuals have been known to enhance calcium retention.

\section{EFFECTS ON THE CENTRAL NERVOUS SYSTEM}

(1) Excess thyroid hormone leads to increased nerve irritability and shortening of the reaction time. Lack of thyroid influnce leads to opposite effects.

(2) Electroencephalographic tracings show slower wave activity in hypothyroidism. Hormone therapy restores norinal alpha wave tracings.

(3) Mental development is arrested or retarded in the absence of thyroid hormone. Thyroid therapy can correct these defects unless the CNS has been lacking in the normal developmental stimulus of thyroid hormone for some time.

(4) Autonomic Nervous System: (a) In hyperthyroid states there is evidence of enhanced adrenergic and cholinergic activity. This is probably brought about by sensitizing the target organs to effects of the normal physiological transmitter. (b) The relationship between the actions of the thyroid hormones and those of the circulating catecholamines has already been discussed.

\section{E. EFFECTS ON THE CARDIOVASCULAR SYSTEM}

Thyroid hormones affect the circulation in the following ways:

(1) There may be direct stimulation of the myocardium as shown by the increased heart rate and stroke volume. Lack of the hormone produces opposite effects.

(2) The action may be indirect, though the sympathomimetic effect of the enhanced sensitivity to epinephrine and norepinephrine, the effects of which prevail over the effect of enhanced sensitivity of the parasympathetic system, as far as the heart is concerned.

(3) Excessive amounts of thyroid hormone lead to peripheral vasodilatation secondary to the increased oxygen consumption and also as a part of the heat regulatory mechanism, to help heat loss.

The systolic blood pressure is elevated in hyperthyroidism while the diastolic pressure is slightly decreased thus leading to high pulse pressure and capillary pulsations.

\section{F. EFFECTS ON TOTAL RED CELL MASS ${ }^{70}$}

A significant increase in total red cell mass was found in thyrotoxic subjects and a significant increase in myxoedema. In both conditions, treatment produces a return of red cell mass / lean body mass relation towards normal.

The red cell mass was found to be closely related to basal oxygen consumption in both conditions. Evidence was found that red cell mass is regulated by changes in basal oxygen consumption and not by a direct action of the thyroid hormone on the bone marrow, and it is suggested that this is the mechanism governing the RBC mass / lean body mass relation in normal subjects.

Thyrotoxicosis is thus accompanied by polycythaemia, which represents a physiological hypertrophy of the red cell mass in response to increased oxygen demands (producing a state of relative anoxia), and myxoedema by anaemia, 
which again represents a physiological readjustment in the oxygen carrying power.

\section{Management of Hyperthyroid Patients}

Hyperthyroid patients requiring an anaesthetic for surgical removal of the thyroid, or for other surgical procedures unrelated to the thyroid gland itself, provide a certain degree of challenge to the anaesthetist. A clear understanding of the underlying abnormalities and peculiarities of these patients would help the anaesthetist to conduct smooth and safe anaesthesia, with minimal operative and postoperative complications, and enable him tó diagnose and deal efficiently with emergencies arising during the operation or in the immediate postoperative period.

\section{Peculiar Aspects of Hyperthyroidism ${ }^{65,71}$}

\section{A. NERVOUS MANIFESTATIONS}

(1) Excessive nervousness and restleşsness.

(2) Psychotic manifestations are often encountered. Thyrotoxicosis is not the cause of the psychosis, but merely elicits a latent one or aggravates an existing mental disorder.

\section{B. THYRÖ́TOXIC HEART DISEASE}

Thyrotoxicosis commonly produces simple physiological overactivity of the heart. However, severe degrees of involvement may be associated with organic changes such as cardiac enlargement and congestive heart failure. Thyrotoxic males show a higher percentage of cardiac involvement than females. The thyrotoxic state affects the heart in numerous ways:

(1) Increased metabolic activity and oxygen consumption lead" to elevated cardiac output, and later to hypertrophy, dilatation and cardiac failure.

(2) Direct toxic effects of excessive thyroxine on the myocardium as well as the arteriovenous shunts owing to dilated thyroid vessels lead to more myocardial strain.

(3) Atrial fibrillation occurs in 6-12 per cent of cases and adds more strain on the heart. When congestive failure supervenes, the incidence of atrial fibrillation shows a great increase.

One of the mortifying aspects of thyrotoxic heart disease is the fact that it responds very poorly to the conventional line of treatment for heart failure or arrhythmias, and unless the thyrotoxic condition is corrected first by surgery or antithyroid drugs, the use of digitalis or quinidine will produce very little or no improvement in the cardiac condition.

\section{GASTROINTESTINAL MANIFESTATIONS}

(1) Vagal overactivity leads to intestinal hypermotility and diarrhoea which may be severe enough to produce some degree of dehydration.

(2) Liver damage occurs frequently in severe thyrotoxicosis. This is attributed 
to the loss of liver glycogen through the glycogenolytic effect of thyrotoxicosis as well as to hypovitaminosis $\mathrm{B}$, particularly thiamine deficiency.

\section{ABNORMALITIES IN HEAT REGULATION}

Heat production is increased owing to the higher rate of oxidative processes, This is usually counterbalanced by the increased heat dissipation through the dilated vessels in the skin and through evaporation of perspiration, the production of which is definitely increased in hyperthyroidism.

Drugs which interfere with the production of perspiration such as atropine can abolish a very important channel for heat loss and may lead to an alarming rise in temperature.

Heat regulation is frequently imperfect, and these patients may show some rise of temperature or even a very high fever as in thyroid crisis.

\section{E. MUSCULAR SYSTEM ABNORMALITIES}

Generalized muscular weakness is not uncommon in thyrotoxicosis and, in some cases, weakness together with muscle wasting dominate the clinical picture, giving rise to the so-called thyrotoxic myopathy. In such cases every effort should be made to exclude myasthenia gravis. This is particularly important because 5 per cent of cases of myasthenia show co-existing thyrotoxicosis. This incidence is much higher than in the general population, but the underlying relationship is still obscure.

No anaesthetist need be reminded that it can be quite catastrophic if an underlying myasthenia is not detected or is considered as nothing more than thyrotoxic myopathy which, unlike myasthenia, does not affect the myoneural junction and is mainly due to abnorm $c^{\prime}$ creative metabolism and impaired phosphocreatine synthesis in the muscle.

\section{F. MECHANICAL EFFECTS OF THE ENLARGED GLAND}

The size of the goitre is in no way indicative of the severity of the thyrotoxic condition. A markedly enlarged gland can compress the trachea or soften its walls, rendering the patient liable to sudden respiratory obstruction under anaesthesia.

More dangerous still is the presence of a retrosternal or intrathoracic goitre, which is even more liable to cause mechanical compression of the trachea than an ordinary neck goitre.

\section{Anaesthetic Management}

\section{A. FOR THYROIDECTOMY}

1. Preoperative Management. Thyrotoxic patients scheduled for surgical removal of the thyroid should be thoroughly investigated and prepared for surgery.

(a) Investigation: (i) Assessment of the degree of thyroid hyperfunction, e.g., radio iodine uptake and serum protein-bound iodine. (ii) Thorough cardiovascular examination to assess the extent of involvement of the heart. (iii) In 
severe thyrotoxicosis, liver function tests may be required. (iv) In the presence of thyrotoxic myopathy the patient should be investigated for the presence of myasthenia gravis. ( $v$ ) Plain chest $x$-ray is essential for detection of retrösternal goitres. (vi) Thorough assessment of the patient's history to elucidate the following points: history of episodes of choking or marked dyspnoea which may indicate excessive pressure on the trachea or the presence of retrosternal goitre; history suggestive of congestive heart failure or arrhythmias; history suggestive of incipient thyroid crisis; history of external irradiation therapy, since this might have produced excessive scarring and deformity of the trachea; history of previous operations on the thyroid because of the possibility of injury to one recurrent laryngeal nerve.

(b) Preoperative preparation of the patient. ${ }^{65,72}$ The purpose of preoperative preparation is to render the patient as euthyroid as possible and to correct, if possible, any other abnormalities.

(i) Antithyroid therapy. The drugs of choice are propylthiouracil, methylthiouracil and tapazol. The treatment should be sufficiently prolonged to gain the best control possible of the signs and symptoms of thyrotoxicosis. The patient must be under constant and careful medical care to avoid or check any toxic manifestations of the thiourea therapy. It must be realized, however, that antithyroid drugs of the thiourea group do not produce involution of the gland. The hyperplasia and excessive vascularity persist or may even increase, and this may add to the difficulty and length of the operative procedure. A course of iodine in the form of Lugol's solution for 10 to 15 days prior to surgery will ensure proper involution of the gland and render it much less vascular.

(ii) Rest. This includes mental and physical rest. These patients are apt to be irritable and every effort should be made to avoid upsetting them. Prolonged bed rest is also advisable but should not be strictly enforced all day as this may make the patient weak and restless.

(iii) Sedation. Sedatives should be used freely, especially in the early stages of treatment. Barbiturates are particularly valuable in this respect. They produce very adequate sedation and some of them may even possess definite antithyroid effects.

(iv) Correction of dietary deficiencies: (1) There should be adequate caloric intake to compensate for the high level of tissue metabolic processes. (2) Food rich in carbohydrates and proteins is desirable in order to replenish the liver glycogen and correct any existing hepatic malfunction. However, strict dietary rules should not be insisted upon as this may make the patient more irritable. (3) Hypovitaminosis $\mathrm{B}$ complex and $\mathrm{C}$ should be corrected. The latter vitamin is supposed to diminish the excessive creatine excretion. (4) Thyrotoxic patients frequently show evidence of dehydration of varying severity and fluid intake should be increased to allow for the excess loss in the form of perspiration and/or diarrhoea.

(v) Stealing the thyroid. This term is used in reference to the practice of keeping the patient unaware of the exact date and time of the operation. A week before the proposed date, the patient would be given an intravenous 
injection of glucose or saline regularly every morning; on the morning of the operation, enough thiopental sodium to put the patient to sleep would be given instead, thus sparing the patient the agony and apprehension of waiting for surgery. Rectal Avertin (tribromethanol) was also used for the same purpose, in which case the patient was given a small enema of a bland solution every morning for a week before the operation.

Nowadays, "stealing the thyroid" is not often resorted to. Proper sedation with barbiturates and the various tranquillizing agents usually renders the patient very co-operative. However, one may occasionally come across a patient who is exceptionally apprehensive and nervous, in which case it would be advisable to use the more subtle approach of "stealing the thyroid."

(vi) Excessive bleeding and oozing may still 'occur despite the fact that the thyrotoxic condition has been controlled before the operation. The anaesthetist should insist on having enough cross-matched blood available at the time of the surgery.

(c) Premedication:

(i) The night before surgery. It is advisable to increase the dose of the usual bedtime sedative to ensure a good night's sleep prior to the day of operation. If the anaesthetist intends to use chlorpromazine to supplement the anaesthetic, a test dose of about $5 \mathrm{mg}$. intramuscularly should be given the day before. If marked tachycardia develops, chlorpromazine should be avoided altogether.

(ii) Morning of the operating day. (1) Sedatives: In view of the high level of reflex activity in thyrotoxic patients, a strong narcotic agent $/$ is desirable. Morphine or omnopon are the drugs of choice. (2) Anticholinergic drugs: These drugs can produce marked tachycardia and may also precipitate a rise of temperature owing to their skin drying effects. However, scopolamine in small doses may be well tolerated by the patient, who will also benefit from the sedative effect of this drug. (3) Phenothiazine derivatives: These drugs offer the advantage of sedation without respiratory depression and some antithyroid activity as well. Their use as a premedicant is commendable provided that they do not produce excessive tachycardia.

2. Anaesthetic Technique. The choice of a particular anaesthetic technique or agent depends entirely on the anaesthetist's preference. Most anaesthetic agents and techniques have been used with equally good results in the hands of anaesthetists who are accustomed to using them. However, there are certain features common to all techniques which are essentially dictated by the peculiarities of the thyrotoxic state: $(a)$ These patients require a higher percentage of oxygen in the anaesthetic mixture in order to satisfy the high oxidation rate in their tissues. (b) Surgical removal of the thyroid gland very seldom requires deep levels of anaesthesia. (c) The patient should be very lightly draped. Heavy drapes will interfere with heat loss and may precipitate hyperpyrexia. $(d)$ The eyes should be protected with ointment or liquid paraffin. If the exophthalmos is severe, it may be necessary to put a special guard over the eyes to protect them from drying and mechanical trauma. (e) The patient should be watched very closely for any signs of respiratory obstruction or abnormal cardiac rhythms. 


\section{Sample Technique}

Anaesthesia is induced with thiopental sodium, a short acting relaxant is then given and the larynx and trachea thoroughly sprayed with 4 per cent Lignocaine. A rather firm endotracheal tube is passed under direct vision laryngoscopy, avoiding as much as possible any trauma to pharynx, larynx or trachea. Anaesthesia is then maintained with nitrous oxide, oxygen and minimal halothane. Intravenous meperidine is used intermittently in small doses as a supplementary agent.

General Anaesthesia versus Regional Analgesia. Regional analgesia, whether in the form of deep cervical block, superficial cervical block or simple infiltration with a local anaesthetic agent, is still used in some places, particularly wherever the surgeon does his own anaesthesia. Regional analgesia is not a good choice for thyroidectomy. It might be justifiable in cases where there is a small circumscribed nodule in a nontoxic patient, but in a thyrotoxic patient with diffuse enlargement of the gland, any regional technique, even if it is adequate, will still cause a great deal of apprehension to the patient, who might get so restless and excitable as to compel the surgeon to abandon the operation.

Endotracheal versus. Mask Anaesthesia. There is a great deal of controversy over this point. Anaesthetists who prefer one or the other technique claim all sorts of advantages for their favourite technique. In summary, the arguments are as follows:

For intubation: (a) perfectly clear airway at all times, with minimal resistance to breathing; $(b)$ protection of the airway from sudden collapse of a softened trachea or the pressure of a retrosternal goitre; $(c)$ the anaesthetist is out of the way of the surgeon and his assistants.

For the use of mask anaesthesia: (a) no possibility of trauma to larynx or trachea; $(b)$ as the operation can be performed at a light plane of anaesthesia, the anaesthetist need not maintain a deeper level merely to prevent the patient reacting on the tube; $(c)$ some surgeons claim that a spasm of the vocal cords producing a crowing sound would warn them that they are handling the recurrent laryngeal nerve!

\section{Management of Complications during Anaesthesia:}

(a) Respiratory obstruction. This may be due to used.

(i) collapse or kinking of a softened trachea particularly if no tube is

(ii) faulty anaesthetic technique such as bronchial intubation, the use of a cuff on a soft endotracheal tube, kinking of the tube in mouth or pharynx, etc. All these mishaps are avoidable and should not occur.

(iii) One of the most serious causes of respiratory obstruction is the presence of a retrosternal goitre pressing on the trachea, especially if both surgeon and anaesthetist are not aware of it. Valuable minutes would be wasted checking other possible causes of obstruction before realizing what is actually happening. In most cases, the surgeon can mobilize the goitre from behind the sternum thus relieving the obstruction. Occasionally, however, the thyroid becomes so engorged that this manual mobilization cannot be done fast enough; 
the writer has seen two such cases, where the surgeon had to split the sternum in a hurry to save the patient's life.

(b) Cardiac complications. Cardiac arrhythmias and severe tachycardia are liable to occur during operation, particularly if the patient was not properly controlled beforehand. They are often associated with other signs of acute thyrotoxic exacerbation such as sudden pyrexia, tachypnoea and sweating.

The treatment should include antithyroid measures as well as the conventional anti-arrhythmia ones. Thus the patient should be given fluids, sedatives and hydrocortisone intravenously. Cooling should be started if the temperature is rising. Lugol's iodine (50-60 minims in 1,000 ml. glucose in water) intravenously is helpful. Anti-arrhythmia drugs are seldom helpful, but intravenous procaine amide could be tried.

Some such casses deteriorate despite all measures, in which case the anaesthetist should not hesitate to ask the surgeon to stop the operation as soon as possible.

Acute cardiac failure may also occur during the operation and presents a very grave problem to the anaesthetist. The problem is particularly grave if the patient has had some digitalis during the preoperative period, and in this case aminophylline should be used. In all cases the operaiton should be abandoned as soon as possible. Needless to say, proper preoperative preparation of the patient rendering him or her as euthyroid as possible is the best safeguard against dangerous cardiac complications.

(c) Air embolism. This is due to the presence of markedly engorged veins in the thyroid. The head-up position usually used in these cases makes it possible for air to be sucked into an open vein. If this happens the patient's head should be lowered and the wound flooded with saline. There should be no hesitation to open the chest and massage the heart if cardiac arrest is suspected.

(d) Excessive haemorrhage and shock. Excessive bleeding is very liable to occur if the patient was not properly controlled beforehand, or if the thiouracil therapy was not followed by a course of iodine therapy. Here again, measures should be taken to correct as much as possible excessive thyroidal activity as well as to replace blood loss. If, despite these measures, excessive bleeding still persists, the operation should be stopped.

\section{B. FOR ELECTIVE EXTRATHYROID SURGERY}

The same preoperative preparation and management mentioned for thyroidectomy applies to extrathyroidal operation, although most of the complications encountered in thyroidectomy are less likely to occur if the site of surgery is away from the thyroid.

\section{FOR EMERGENCY SURGERY}

Emergency surgery for uncontrolled thyrotoxic individuals presents a grave risk to the patient and a serious problem to anaesthetist and surgeon. Such patients should not be subjected to the stresses of anaesthesia and surgery unless the procedure is life saving and absolutely necessary. 
1. Preparation of the Patient and Premedication. It is quite obvious that proper preparation of the patient, as far as the thyrotoxic condition is concerned, is out of the question. All the anaesthetist can hope to achieve is stabilization of the patient's condition as much as possible in the short time available.

(a) Rectal or intravenous Lugol's iodine is one of the essential steps to be taken.

(b) The use of phenothiazine derivatives intravenously may be helpful in ameliorating the thyrotoxic condition to some extent, although the danger of producing severe tachycardia is a very real one.

(c) If the thyrotoxic manifestations are pronounced controlled. hypothermia should be started at once. The patient should be kept cool throughout the operative and immediate postoperative periods. A temperature of $33^{\circ} \mathrm{C}$. is quite adequate in most cases. The advantages of hypothermia in thyrotoxicosis are as follows: (i) lowers thyroid activity; (ii) diminishes the high level of oxidative processes in the tissues and consequently the oxygen requirements; (iii) minimizes the possibility of postoperative thyrotoxic storm.

(d) Dehydration and electrolyte inbalance should be corrected as much as possible. Hydrocortisone hemi-succinate intravenously would help reduce thyroidal overactivity. Parentral administration of vitamines $B$ and $C$ is also advisable.

(e) Adequate premedication with pentobarbitone and morphine is desirable. If the patient is still dehydrated the dose of scopolamine should be reduced.

2. Anaesthetic Management. A local or regional technique should be considered in every case unless the site of operation does not permit. A continuous peridural block is a very good choice for emergency laparotomy. As has been mentioned before, some workers believe ${ }^{38}$ that a large number of the thyrotoxic manifestations are due to sensitization of the tissues to the effect of catecholamines. The same workers suggested peridural or subarachnoid block as a line of therapy for thyroid crisis regardless of whether the patient requires surgery or not. Intravenous pentobarbital can be used with thése regional techniques to alleviate the patient's apprehension and ensure his co-operation.

3. Management of Operative Complications. All the operative complications encountered during thyroidectomy (see above), are liable to occur in unprepared thyrotoxic patients, with greater frequency and increased severity. The management of such complications has been discussed before.

\section{Management of Postoperative Complications}

\section{A. TRACHEITIS}

This occurs commonly after thyroidectomy and varies in severity from case to case. Whether this tracheitis is due to baring of the trachea as well as some trauma because of surgical handling during the operation or to irritation caused by an endotracheal tube, is subject to a great deal of controversy.

A series of thyroidectomies are being done in our department using a mask instead of an endotracheal tube, in an attempt to find out whether avoiding the 
use of a tube would produce statistically significant reduction in the incidence of tracheitis. However, it is too early yet to try to draw any conclusions from this study.

Another plausible cause of post-thyroidectomy tracheitis is injury to the superior laryngeal nerve.

Management. Following the operation, the patient should be put in an oxygen tent with high percentage of humidity. If cough is too irritating, codeine should be given to ensure adequate rest for the patient. If, as occasionally happens, the picture is further complicated by the development of laryngeal oedema, tracheostomy should be done immediately.

\section{B. RESPIRATORY OBSTRUCTION}

This can be ctue to adductor spasm of the vocal cords following a bilateral recurrent laryngeal nerve injury, because the abductor muscles become paralysed immediately following the injury while the adductor muscles retain their tone for some time. Unilateral recurrent laryngeal injury very seldom leads to respiratory obstruction. A less common cause of obstruction is collapse of a softened trachea, or pressure on the trachea by blood accumulating under the pretracheal fascia.

Management. No time should be wasted trying to discover the cause. The patient should be immediately tracheotomized.

\section{TETANY}

Extensive removal of the thyroid glands may lead to destruction of the parathyroid glands, hypocalcemia and signs and symptoms of tetany. This mishap is more liable to occur in operations for recurrent hyperthyroidism when the anatomy of the area has been distorted by previous surgery.

Management. Calcium chloride $0.5 \mathrm{gm}$. intravenously dramatically clears the manifestations of tetany. Proper replacement therapy with parathyroid hormone may be required later.

\section{THYROTOXIC CRISIS OR STORM}

This is the most dangerous complication of thyrotoxicosis. It can occur after thyroidectomy, although nowadays this is most unlikely because of proper preoperative preparation of the patient. It also occurs after extrathyroidal operations on an uncontrolled thyrotoxic patient, or without any surgica provocation whatever, the so-called "medical" thyroid storm.

Whatever the cause of the crisis, the anaesthetist with his superior knowledge of physiology, pharmacology and the various techniques of maintaining a clear airway and inducing hypothermia, should be a most valuable member of any team dealing with such cases.

Management. This subject can be discussed under the following headings:

1. Measures to Combat Hyperpyrexia. Although some cases bf thyrotoxic crisis are not pyrexic, the majority are. Controlled hypothermia should be started immediately with the object of maintaining a temperature of $33^{\circ}-35^{\circ} \mathrm{C}$, 
Apart from combatting the hyperpyrexia, hypothermia also helps in depressing thyroidal overactivity.

2. Measures to Combat Restlessness. Extreme restlessness is a common feature of the majority of these cases and usually leads to pronounced exhaustion.

Barbiturates in the form of pentobarbital intramuscularly or thiopental intravenously or rectally in repeated doses, help to combat the restlessness and facilitate the induction of hypothermia. Phenothiazine derivatives can also be used, provided that they do not aggravate the tachycardia. Chloral hydrate, rectal avertin (tribromethanol) and paraldehyde have all been tried with favourable results.

3. Replacement Therapy. (a) Excessive fluid and electrolyte loss through diarrhoea and/or vomiting should be corrêcted with normal saline and 5 per cent glucose in water. $(b)$ Hypovitaminosis $\mathrm{B}$ complex and $\mathrm{C}$ should be corrected with large doses of vitamin B complex and C parenterally.

4. Measures 'to reduce thyroidal hyperactivity and combat the peripheral effects of excessive thyroxine: (a) Large doses of potassium iodide (1.5-2.5 g. day) orally or intravenously or Lugol's iodine intravenously (50 minims/1000 ml. glucose in water) are very helpful. (b) Intravenous hydrocortisone hemisuccinate in repeated doses of $100 \mathrm{mg}$. ACTH is reported to be as effective as hydrocortisone. ${ }^{73}(c)$ Sympathetic blockade using continuous peridural analgesia has been suggested by Brewster et al..$^{38}(d)$ Oddly enough, Mahaux, who considered the thyrotoxic crisis as being due to hypothyroxinemia, gives his patients small doses of thyroxine (2-5 mg.) with favourable results..$^{74,75}$

5. Measures to Combat Infection. Infection can be a precipitating factor in the causation of the crisis, particularly a "medical" one, and proper antibiotic coverage is essential if the crisis is to be controlled.

\section{Management of Hypothyroid Patients}

Lowered thyroid function can be due to several causes: (1) congenital absence of thyroid; (2) atrophy of the gland; (3) extensive thyroidectomy or chronic thyroiditis; (4) secondary to hypopituitarism.

Hypothyroidism occurring in infancy and childhood gives rise to Cretinism, while myxoedema is usully the result of hypofunction un adult life.

The occurrence of generalized myxoedema indicates hypothyroidism, but hypothyroidism can exist without any myxoedematous manifestations.

\section{Peculiar Aspects of Hypothyroidism ${ }^{65}$}

\section{A. NERVOUS MANIFESTATIONS}

Hypothyroid patients are usually mentally dull, drowsy and apathetic. Psychosis and hallucination are also occasionally encountered.

\section{B. CARDIO-VASCULAR MANIFESTATIONS}

1. Myxoedema Heart Disease. ${ }^{71}$ Myxoedema leads to cardiac dysfunction in approximately 75 per cent of all untreated cases. This can occur at any age and 
has no sex predominance. Cardiomegaly is the most important finding and is caused partly by the myxoedematous state of the cardiac structures and partly by some degree of hydropericardium and cardiac dilatation which may develop which may develop to such an extent as to cause relative mitral and tricusped insufficiency.

2. Peripheral Circulation. Generalized atherosclerosis is a common factor of myxoedema. Whether this is due to the high blood cholesterol levels or to some other factor, is not clear yet. The skin vessels are constricted in an effort to minimize heat dissipation. It is very important to realize that, quite often, these patients are free of cardiac symptoms because the hypometabolic state masks them until the process is long standing or well advanced. Indeed, even then, the patient may have no complaints until some sudden demand is thrown upon the decreased cardiac reserve. The symptoms, when and if they occur, in the form of dyspnoea, which becomes worse as the heart failure progresses, and precordial or anginal pain due to the frequent association of coronary arteriosclerotic disease.

Anginal pain may also occur following moderate or intensive thyroid therapy in these patients because of the increased tissue metabolism, with which the heart cannot cope.

The signs of cardiac involvement are bradycardia, cardiac enlargement and manifestations of congestive failure. The E.C.G. is fairly characteristic. There is sinus bradycardia, low voltage QRS complexes and absent or inverted $T$ waves in all leads. There may be varying degrees of atrioventricular block.

Therapeutic tests with specific therapy produce striking results and are diagnostic of the myxoedematous origin of the cardiac disease. The only effective treatment for myxoedema heart disease is very small doses of thyroid extract, not exceeding 0.5 grain daily. Digitalis and diuretics have no distinct influence on the course of the disease.

\section{HAEMATOLOGICAL MANIFESTATIONS}

Myxoedematous patients very commonly suffer from normocytic, normo- or hypochromic anemia which could be due to depression of the erythroblastic bone marrow. These anaemias usually respond to thyroid therapy, although they may require iron therapy as well.

Aplastic anaemia may also occur in association with myxoedema.

\section{MANIFESTATIONS OF FLUID AND ELECTROLYTE DISTURBANCES}

Water and sodium retention are common features of myxoedema. Mucoproteins are added to the retained water in the corium of the skin, giving rise to the characteristic non-pitting oedema of myxoedema.

\section{E. MISCELLANEOUS MANIFESTATIONS}

(1) Unsuspected pleural effusion occasionally occurs in myxoedematous patients. The anaesthetist should be on the watch for respiratory symptoms and signs suggestive of fluid in one or both pleural spaces. 
(2) Hypothyroid patients are very sensitive to narcotics and central nervous system depressants in general.

\section{Anaesthetic Management}

\section{Preoperative Management}

(a) Proper history should be taken to find out whether the patient has had manifestations suggestive of cardiac involvement, anginal pains or some specific intolerance to drugs. History taking in these patients is not a simple matter; indeed it can be quite difficult or impossible, in which case one may have to rely on the relatives or nursing staff.

(b) Thorough physical examination should be done on any patient suspected of suffering from hypothyroidism.

The anaesthetist should be particularly interested in the following: (i) presence and degree of cardiac involvement; (ii) presence and degree of hydropericardium; (iii) E.C.G. tracing for signs of old infarcts or severe coronary artery involvement; (iv) presence and severity of anaemia, which should be corrected as much as possible; ( $v$ ) presence and degree of pleural effusion; (vi) response of the patient to thyroid extract and whether he develops anginal pain from the specific therapy.

(c) Premedications. These patients are usually sluggish and sleepy and do not require heavy sedation before operation. Atropine and minimal doses of morphine or meperidine are the drugs commonly used. If the patient is scheduled for major surgery, a cut down should be done ahead of time. Veins in these patients are hard to find owing to the myxoedematous changes in the skin. Care should be taken, however, to avoid over-transfusing them, and the use of packed red blood cells is preferable to whole blood fransfusions.

2. Anaesthetic Technique. The choice of agent and technique is up to the anaesthetist. It is wise to avoid the use of large doses of drugs: It is also important to realize that hypothyroid patients are liable to become hypothermic, and every effort should be made to avoid undue loss of heat.

Hypothermic Myxoedema Coma. ${ }^{76,77,78,79}$ Some twenty cases of hypothermia associated with myxoedema have been described in the last six or seven years, mainly from Britain and Ireland. The use of sensitive thermocouple thermometers in recent years is probably responsible for the detection of these cases, which would have been missed if an ordinary medical mercury thermometer was used. Usually, there are marked myxoedematous 'manifestations, but occasionally these may not be well defined-in which case the diagnosis of cerebrovascular accident is usually put forward unless the hypothermia has been noted.

The prognosis in these cases is very unfavourable. Most of them die of heart failure.

The usual line of treatment is as follows:

(a) Warming. Actual surface heating with hot water or air should be avoided as this may precipitate heart failure. Nursing the patient between blankets is all that is required.

(b) Thyroid hormone therapy. This is the specific treatment. The fast- 
acting triiodothyronine compounds are preferred to the slow-acting thyroxine, at least in the early periods of treatment. The dose of triiodothyronine to be used is subject to some controversy. Some workers believe that small doses should be used to avoid raising the metabolism too fast, which would be more than the myxoedematous heart could cope with. On the other hand, two of the cases that survived were treated with large doses of trijodothyronine intravenously and sublingually, and MacDonald feels that it is possible that in myxoedema coma the low temperature results in better tolerance of these drugs.

(c) Cortisone acetate $50 \mathrm{mg}$, intramuscularly every 4 hours.

(d) Antibiotics.

(e) Fluid intake should be closelyl watched.

A case of hypothermia was reported in a myxoedematous patient who was given chlorpromazine to control a state of acute psychosis. ${ }^{80}$

\section{RÉSUMÉ}

Le rapporteur a discuté des aspects physiologiques et pharmacologiques de la fonction de la glande thyroide. Cette discussion va jusqu'à parler des détails de la biosynthèse et du sort des hormones thyroidiennes, des facteurs influençant la fonction de la glande thyroide et des actions physiologiques et pharmacologiques des hormones thyroidiennes.

L'auteur parle ensuite de la conduite à suivre pour l'anesthésiste en présence des malades hyperthyroidiens et des malades hypothyroidiens, et, cela, en détail, y compris les soins préopératoires, opératoires et postopératoires et il parl aussi du traitement des complications.

\section{REFERENCES}

1. Solomon, D. H., \& Dowling, J. T. The Thyroid. Ann. Rev. Physiol. 22: 615 (1960).

2. De Groot, L. J. Physiology of the Thyroid Gland. Postgrad. Mede 24: 170 (1958).

3. Hamolsky, M. W., \& Freedrerg, A. S. The Thyroid Gland. New Eng. J. Med. 262(1): $23(1960)$.

4. Greer, M. A. Studies on the Influence of Central Nervous System on Anterior Pituitary Function. Rec. Prog. Hormone Res. 13: 67-104 (1957).

5. Von Euler, C., \& Holmgren, B. The Thyroxine "Receptor" of the Thyroid-Pituitary System. J. Physiol. (London) 131: 125 (1956).

6. YAMADA, T. \& Greer, M. A. Studies on the Mechanism of Hypothalamic Control of Thyrotropin Secretion: Effect of Thyroxine Injection into the Hypothalamus or the Pituitary on Thyroid Hormone Release. Endocrinology 64: 559 (1959).

7. Johnson, D. E., Solomon, D. H., \& Greer, M. A. The Effect of Triodothyronine and Thyroxine upon the Rate of Release of Thyrodd Hormone in Various States. J. Clin. Endocrinol. \& Metab. 19: 317 (1959).

8. Adams, D. D., \& Purves, H. D. The Role of Thyrotrophin in Hyperthyroidism and Exophthalmos. Metabolism 6: 26 (1957).

9. Dobyns, B. M., \& Steelman, S. L. Thyroid Stimulating Hormone of Anterior Pituitary as Distinct from Progressive Exophthalmos-producing Substance. Endocrinology 52: 705 (1953).

10. Wolstenholme, G. E. W., \& Millar, E. C. P. The Thyroid Gland. Ciba Foundation Colloq. on Endocrinol. 10: 303. (1957).

11. Had,Mi, N. S., \& Stueckle, R. G. Problems of Thyroidal Self Regulation. Metab., Clin. \& Exper. 5: 646 (1956). 
12. Astwood, E. B., \& Bissell, A. Effect of Thiuracil on Iodine Content of Thyroid Gland. Endocrinology 34: 282 (1944).

13. Solomon, D. H. Factors Affecting the Fractional Rate of Release of Radio Iodine from the Thyroid Gland in Man. Metab., Clin. \& Exper. 5: 667 (19:56).

14. Goodman, L. S., \& Gilman, A. The Pharmacological Basis of Therapeutics. 2nd ed., New York: The Macmillan Co. (1955).

15. Glaton, V. A., \& PitT-Rivers, R. The Effect of Excessive Iodine on the Thyroid of Rat; Endocrinology 64: 835 (1959).

16. Paley, K. R., Sobel, E. S., \& Yalow, R. S. Some Aspects of Thyroidal Iodine Metabolism in a Case of Iodine-Induced Hypothyroidism. J. Clin. Endocrinol. \& Metab. 18: 79 (1958).

17. Goldsmith, R., Herbert, C. \& Lutsch, G. The Efffect of Iodide on the Release of Thyroid Hormone in Hyperthyroidism: Further Observations, J. Clin. Endocrinol. \& Metab. 18: 367 (1958).

18. Greer, M. A., \& De Groot, L. J. The Efflect of Stable Ibdide on Thyroid Secretion in Man. Metab., Clin. \& Exper. 5: 682 (1956).

19. Hamolsky, M. W., \& FreEdberg, A. S. The Thyroid Gland. New Eng. J. Med. 262(3): $129(1960)$.

20. Kydd, D. M., \& MAN, E. B. Precipitable Iodine of Serum (SPI) in Disorders of Liver. J. Clin. Investigation 30: 874 (1951).

21. Hill, S. R., Jr.; Reiss, R. S.; Forsham, P. H.; \& Thorne, G. W. Effect of Adrenocorticotrophin and Cortisone on Thyroid Function-Thyroid-Adrenocortical Inter-relationship. J. Clin. Endocrinol. 10: 1375 (1950):

22. Ingbar, S. H.; Freinkel, N.; Dowling, J. T.; \& Kumagai, L. F. Abnormalities of Iodine Metabolism in Euthyroid Relatives of Patients with Graves' Disease. J. Clin. Investigation 35: 714 (1956).

23. Wyngaarden, J. B., Wright, B. M., \& Ways, P. Effects of Certain Anions upon Accumulation and Retention of Iodide by Thyroid Gland. Endocrinology 50: 537 (1952).

24. Stanbury, J. B., \& Wyngaarden, J. B. Effect of Percholate on the Human Thyroid Gland. Metabolism 1: 533 (1952).

25. Jaimet, C. H., \& Thode, H. G. Thyroid Function Studies on Children Receiving Cobalt Therapy. J.A.M.A. 158: 1353 (1955).

26. Best, C. H., \& Taylor, N. B. The Physiological Basis of Medical Practice. 6th ed., Baltimore: Williams and Wilkins (1955).

27. Bogdanove, E. M., \& D'Angelo, S. A. The Effects of Hypothalamic Lesions on Goitrogenesis and Pituitary TSH Secretion in Propylthiouracil Treated Guinea Pig. Endocrinology 64: 53 (1959).

28. Ganong, IV. F., Fredrickson, D. S., \& Hume, D. M. The Effect of Hypothalamic Lesions on Thyroid Function in the Dog. Endocrinology 57: 355 (1955).

29. KNigge, K. M., \& Bierman, S. M. Evidence of Central Nervous System Influence upon Cold-induced Acceleration of Thyroidal I131 Release. Am. J. Physiol. 192: 625-630 (1958).

30. Shibusawa, K.; Saito, S.; Nishi, K.; Yamamoto, T.; Abe, C.; \& Kawai, T. The Effects of. Goitrogens on the Hypothalamic Neuro-secretion in Experimental Animals. Endocrinol. Jap. 3: 151 (1956).

31. Li, M. C.; Rall, J. E.; Maclean, J. P.; Lipsett, M. B.; Ray, B. S.; \& Pearson, O. H. Thyroid Function following Hypophysectomy in Man. J. Clin. Endocrinol. \& Metab. 15: 1228 (1955).

32. Shipley, R. A., \& Macintrre, F. H. Effects of Stress, TSH \& ACTH on the Level of Hormonal I131 of the Serum. J. Clin. Endocrinol. \& Metab. 14: 309 (1954).'

3.3. Engstrom, W. W., \& Markardt, B. Effects of Serious Illness and Surgical Stress on Circulating Thyroid Hormone. J. Clin. Endocrinol. \& Metab. 15: 953 (1955).

34. - - The Effects of Stress and Cortisone on the Circulating Thyroid Hormone. J. Lab. \& Clin. Med. 44: 793 (1955).

35. Moore, F. D. Endocrine changes after Anesthesia, Surgery and Unanesthetized Traurna in Man. Rec. Prog. Hormone Res. 13: 511 (1957).

36. Goldenberg, I. S.; Lutevak, L.; Rosenbaum, P. J.; \& Hayes, M. A. Thyroid Activity during Operation. Surg. Gynec. \& Obst. 102: 129 (1956).

37. Oppenheimer, J. H., Wise, H. M., \& Lasley, D. A. The Role of the Thyroid Gland in Experimental Traumatic Shock. J. Clin. Investigation 37: 380 (1958). 
38. Brewster, W. R., Jr.; IsaAcs, J. P.; Osgood, P. F.; \& King, T. L. The Hemodynamic and Metabolic Inter-relationship in the Activity of Epinepherine, Norepinepherine and the Thyroid Hormones. Circulation 13: 1 (1956).

39. Ingbar, S. H., \& Freinkel, N. Symposium on Thyroid: ACTH, Cortisone and Metabolism of Iodine. Metabolism 5: 652 (1956).

40. Wolfson, W. A.; Beierwaltes, W. H.; Robinson, W. P.; Duff, I. F.; jones, J. R.; KNorpp, C. T.; \& EYA, M. Corticogenic Hypothyroidism: Its Regular Odcurrence and Clinical Significance during Prolonged Therapeutic Administration of ACTH or Cortisone. J. Lab. \& Clin. Med. 36: 1005 (1950).

41. Berson, S. A., \& Yalow, R. S. The Effect of Cortisone on the Iodine Accumulating Function of the Thyroid in Euthyroid Subjects. J. Clin. Endocrinol. \& Metab. 12: 407 (1952).

42. SpurR, C. L., Kelly, F. J., \& Allen, H. C. Jr. Serial Observation of I131 Uptake by the Thyroid Following Thyrotropine, Corticotropine and Cortisone. J. Lab. \& Clin. Med. 40: 946 (1952).

43. ZingG, W., \& Perry, F. The Influence of Adrenal and Gonadal Steroids on the Uptake of Iodine by the Thyroid Gland. J. Clin. Endocrinol. \& Metab. 13: 712 (1953).

44. Frederickson, D. S., Forsham, P. H., \& Thorn, G. W. The Effect of Massive Cortisone Therapy on Measurements of Thyroid Function. J. Clin. Endocrinol. \& Metab. 12: 541 (1952).

45. Hardy, J. D., Rregel, C., \& Erisman, E. P. Experience with Protein-bound Iodine (PBI); The Effect of ACTH and Cortisone on Thyroid. Function. Am. J. M. Sc. 220: $290(1950)$.

46. Prera, G. A., Regan, C., \& Werner, S. C. Clinical and Metabolic Study of 17-Hydroxycorticosterone (Kendall compound F); Comparison with Cortisone. Proc. Sod Exper. Biol. \& Med. 77: 326 (1951).

47. Engstrom, W. W., \& Markardt, B. Influence of Estrogen on Thyroid Function. J. Clin. Endocrinol. 14: 215 (1954).

48. Freedrerc. I. M., Hamolsky, M. W., \& Freedberg, A. S. The Thyroid Gland in Pregnancy. New Eng. J. Med. 256: 505 (1957).

49. Berger, M., \& Nelken, S. Le problème du passage de l'hormone thyroidienne à travers le placenta. Clin. obstét. et lab. de phys. biol., Fac. de Méd. Lyon; Presse méd. 66(4): 62 (1958).

50. Freedman, D. D., Robins, J., \& Rall, J. E. Effects of Methyl Testosterone on Thyroid Function, Thyroxine Metabolism and Thyroxine Binding Proteins. J. Clin. Investigation 37: 1027 (1958).

51. DrmL, V. A. Pharmacology in Medicine. 2nd ed., New York: McGraw-Hill (1958).

52. Astwood, E. B. Mechanism of Action of Various Anti-Thyroid Compounds. Ann. New York Acad. Sc. 50: 419 (1949).

53. Pitt-Rivers, R. Mode of Action of Anti-Thyroid Compounds. Physiol. Rev. 30: 194 (1950).

54. RABEN, M. S. Paradoxical Effects of Thiocyanates and Thyrotropin on Organic Binding of Iodine by Thyroid in Presence of Large Amounts of Iodide. Endocrinology 45: 296 (1949).

55. Pitr-Rivers, R., Galton, V. A., \& Halmi, N. S. Nature of Radio-Iodine Not Dischargable with Percholate in the Thyroid Gland of Thiouracil-treated Rats. Endocrinology 63: 699 (1958).

56. Slingerland, D. W.; Graham, D. E.; Josephe, R. K.; Mulviey, P. F. Jr.; Trakas, A. P.; \& YAMAZAKI, E. The Effect of Propylthiouracil on the Conversion of Monoiodotyrosine to Diiodotyrosine. Endocrinology 65: 178 (1959).

57. Richards, J. B., \& Ingbar, S. H. The Effects of Propylthiouracil and Percholate on the Biogenesis of Thyroid Hormone. Endocrinology 65: 198 (1959).

58. Wase, A. W., \& Greenspan, J. Effect of Sodium 5-allyl-5(1 methyl butyl)2 Thiobarbiturate on Uptake of $\mathrm{I}^{131}$ by Rat Thyroid. Proc. Soc. Exper. Biol. \& Med. 84(1): 154 (1953).

59. Wase, A. W., \& Foster, W. C. Thiopental and Thyroid Metabolism. Proc. Soc. Exper. Biol. \& Med. $91: 89$ (1956).

60. Oyama, T. Effects of Anaesthesia on Thyroid Function in Rats. Anesthesiology 18: 719 (1957).

61. - E Effects of Diethyl Ether Anesthesia on Thyroid Function of Rats. Endocrinology 65: 56 (1959). 
62. Mincu, St. M.; Negoescu, I.; Petrsco, C.; Lupulesscu, A.; \& Cocu, F. I. Contribution à l'étude de l'action de la chlorpromazine sur la gland thyroide. Ann. d'endocrinol. 18: $902(1957)$.

63. Parhon, C. I., Aslan, A., \& Bojinescu, I. Effect of Procaine $\mathrm{HCl}$ on Thyroid Function. Stud. Cerc. Endocr. 7: 161 (1956). Excerpt from the Excerpta Medica, Endocrinology, Sec. 3, Vol. 11 (1957).

64. Fontanne, M., \& Lachiven, F. Thyroide et thermoregulation chimique. Arch. d. sc, physiol. 9: 63 (1955).

65. Paschkis, K. E., Rakoff, A. E., \& Cantarow, A. Clinical Endocrinology. 2nd ed., New York: Hoeber (1958).

66. LaRdy, H. A., \& Maley, G. F. Metabolic Effects of Thyroid Hormones in vitro. R̈ec. Prog. Hormone Res. 10: 129 (1954).

67. Wright, S. Applied Physiology. 9th ed.; London: Oxford (1952).

68. Althausen, T. L., Lockhart, J. C., \& Soley, M. H. New Diagnostic Test "Galactose" for Thyroid Disease. Am. J. M. Sc. 199: 342 (1940).

69. Coggeshall, H. C., \& Green, J. A. Influence of Desiccated Thyroid Gland, Thyroxin and Inorganic Iodine upon Storage of Glycogen in Liver of Albino Rat under Controlled Conditions. Am. J. Physiol. 105: 103 (1933).

70. Muldowney, F. P., Crooks, J., \& Wayne, E. J. The Total Red Cell Mass in Thyrotoxicosis and Myxoedema. Clin. Sc. 16: 309 (1957).

71. ReICH, N. E. The Uncommon Heart Diseases. 1st ed.; Springfield, III.: Charles C. Thomfas (1954).

72. Mason, R. L., \& Zintel, H. A. Preoperative and Postoperative Treatment. 2nd ed.; Philadelphia: Saunders (1946).

73. Szillagyi, D. E., McGraw, A. B., \& SMrth, N. P. D. The Effect of Adrenocortical Stimulation on Thyroid Function. Ann. Surg. 136: 555 (1952).

74. Mahaux, J. Les crises hypothyroxinémiques aiguës provoquées par le thiouracil. Acta. clin. belg. 1: 234 (1946).

75. ___ Les crises aiguës des hyperthyrö̈diens; Etude physio-pathologique. Rev. belge sc. méd. 16: 21 (1945).

76. Knyvett, A. F., \&. Steinbeck, A. W. A Case of Myxoedema Coma. M. J. Australia, 1: $722(1957)$.

77. Macdonald, D. W. Hypothermic Myxoedema Coma: Three Case Reports. Brit. M. J. ii: 1144 (1958).

78. Gatensy, P. B., \& Bermungham; A. Hypothermic Myxoedema Coma: Irish J. M. Sc. 402: $283(1959)$.

79. Gordan, G. S. The Year Book of Endocrinology. Chicago: Year Book. Publishers (1959-60).

80. Mrtchell, J. R. A., Surfmge, D. H. C., \& Willison, R. G. Hypothermia after Chlorpromazine in Myxoedematous Psychosis. Brit. M. J. ii. 932 (1959). 